\title{
Investigation of a coupling model of coordination between Xinjiang High-speed Railway and the Tourism Economy
}

\author{
Xiaodan $\mathrm{Li}^{1, \mathrm{a}}$,Lihua $\mathrm{Guo}^{2, \mathrm{~b}}$ \\ ${ }^{1}$ Beijing Jiaotong University Beijing, China
}

\begin{abstract}
Transportation is an important factor affecting the development of tourism economy. With the opening and operation of high-speed railway, tourism has become the highest priority and most direct beneficiary industry. This paper builds a coordination degree model and a coupling coordination degree model (CCDM) for examining the coordination degree of Xinjiang high-speed railway and tourism economy. Results reveal that Xinjiang's high-speed railway and tourism economy have transformed from a moderate imbalance to primary coordination, but it still needs to be improved. Finally, suggestions are made on how to promote the coordinated development of Xinjiang's high-speed railway and tourism economy.
\end{abstract}

\section{Introduction}

On November 16, 2014, the Lanxin High-speed Railway was opened, marking the official integration of Xinjiang into the national high-speed railway economic circle. Xinjiang is very rich in resources, but it is far away from most places. Generally, it is several hundred kilometers from one neighboring city to another. As a brand-new transportation, the high-speed railway suddenly changed people's concept of space and shortened the distance between cities.

Urumqi, Turpan and Hami along the Xinjiang High Speed Railway are well-known tourist destinations. The opening of the high-speed railway has made them very popular. Taking the high-speed railway and watching the scenery has become a fashion, driving the rapid development of the tourism economy of cities along the high-speed railway line.

In 2017, the number of domestic tourists reached 5.001 billion, forming a huge market of 4.57 trillion yuan in domestic tourism revenue. The development of railways has provided more and more convenient transportation for tourism, induced people to travel, and prospered the tourism market. The prosperity and development of the tourism market will continue to bring tourists to the railway. The next 10-15 years will be a period of great development of China's tourism industry, which will provide broad development prospects for the growth of railway passenger traffic.

Therefore, the study of the coupling and coordination between high-speed railway and tourism economy becomes particularly important. This will help us promote the upgrading and transformation of the tourism industry and the development of in-depth tourism.

\section{Literature Review}

High-speed railway (HSR) is a type of railway transport that operates significantly faster than traditional railway traffic. New lines in excess of $250 \mathrm{~km} / \mathrm{hr}$ and existing lines in excess of $200 \mathrm{~km} / \mathrm{hr}$ are considered to be high-speed railway. High-speed railway has brought great impact on many aspects of social \& economic life. Many scholars have conducted numerous research works on the influence of HSR. The research on the relationship between highspeed railway and tourism economy mainly focuses on the analysis of tourists' travel behavior in the context of highspeed railway, the impact of high-speed railway on the change of tourism spatial pattern, the impact of high-speed railway on the construction and planning of tourism industry, the spatial and temporal changes and mechanism in the era of high-speed railway, and the impact of highspeed railway on the tourism economy.

Bonnafous (1987) pointed out that after the opening of the French High Speed Railway (TGV) between Paris and Lyon, tourism demand and supply have changed significantly. The number of tourists between Paris and Lyon has continued to rise, and tourism shopping expenditure has increased significantly [1]. The stimulating effect on the regional tourism economy has been significantly enhanced. H. Okada (1994) analyzed that the trip from Tokyo to Osaka was shortened to 2 hours and 25 minutes after the opening of the Shinkansen in Japan, which greatly increased the desire of residents along the route to travel to Tokyo [2]. The travel rate of residents along the route increased significantly, and the economic effect on Osaka City was obvious. Bruce Prideaux (2000) [3] and Banister (2005) [4] respectively pointed out that the regions along the high-speed railway took advantage of the convenience of travel to promote the development of the regional tourism economy after the 
high-speed railway was opened, and the economic income levels of high-speed railway-connected tourist cities and passing destinations were significantly improved. Paul Peeters (2007) analyzed the high-speed railway transportation system throughout Europe and pointed out that the rapid development of high-speed railway construction and residents' choice of high-speed railway as a travel method further promoted the integration of European countries in economic, social and cultural aspects [5].

Huang (2011) used the new economic geographic model to study the impact of high-speed railway on the development of regional tourism economy [8]. She believed that high-speed railway operations strengthened the economic, cultural, and personnel exchanges between regions, accelerated the flow of people, logistics, capital, and information, optimized resource allocation, and effectively leverage the coordinated advancement of tourism economic and social development strategies in various places. Wu (2014) used three indicators of standard deviation, coefficient of variation, and geographic concentration to analyze and compare the economic differences between Beijing-Tianjin, Jiaoji, and Beijing-Shanghai high-speed railway [9]. She believes that the opening of high-speed railway has a stabilizing effect on the tourism economic differences between cities.

In summary, the relationship between high-speed rail and tourism economy mainly focuses on the study of highspeed rail through changing tourist behavior, improving traffic accessibility, shortening the time to promote the development of regional tourism economy, and changing the spatial pattern and planning of tourism. However, there are few studies on the coupling and coordination state of high-speed rail and tourism economy. In this context, studying the co-integration state of high-speed rail and tourism economy will help the country's planning for high-speed rail construction and the deployment of regional tourism development plans.

Table1. Index system used for evaluation of the relationship between High-speed Railway and the Tourism Economy

\begin{tabular}{|l|l|}
\hline \multicolumn{1}{|c|}{ System } & \multicolumn{1}{c|}{ index } \\
\hline \multirow{4}{*}{ The integration value of High-speed Railway } & Passenger traffic (10000 persons) \\
\cline { 2 - 2 } & Length of Railways in Operation (Km) \\
\cline { 2 - 2 } The integration value of Tourism Economy & Passenger-Kilometers(100millionpassenger-km) \\
\hline & Total Number of Overseas Vistors Arrivals (person) \\
\cline { 2 - 2 } & Number of Domestic Visitors (10000 persons) \\
\cline { 2 - 2 } & Foreign Exchange Earnings from lnternational Tourism (USD 10 000) \\
\cline { 2 - 2 } & Earnings from Domestic Tourism (100 million yuan) \\
\hline
\end{tabular}

- Evaluation of Xinjiang High-speed Railway and the Tourism Economy

We analyzed the level of Xinjiang High-speed Railway and the Tourism Economy quality using the entropy method (Chen et al., 2009). The weight of each indicator was calculated according to information entropy and variations in the indicators. The steps were as follows (formulas (3)-(8)):

The proportion of the indicator $j$ in year $i$ :

$Y_{i j}=X_{i j} / \sum_{i=1}^{m} X_{i j}$

Information entropy of the indicator:

\section{Materials and Methods}

\subsection{Data pre-processing}

The required data were collected from the Statistical Yearbook of Xinjiang (2012-2017). We standardized the data using formulas (1) and (2) and eliminated the influence of dimension, magnitude, and positive and negative orientation.

$$
\begin{aligned}
& \text { Positive indicator: } X_{i j}=\frac{X_{i j}-\min \left\{\mathrm{X}_{j}\right\}}{\max \left\{X_{j}\right\}-\min \left\{\mathrm{X}_{j}\right\}} \\
& \text { Negative indicator: } X_{i j}=\frac{\max \left\{X_{j}\right\}-X_{i j}}{\max \left\{X_{j}\right\}-\min \left\{\mathrm{X}_{j}\right\}}
\end{aligned}
$$

where $X_{i j}$ represents the value of indicator $j$ in year $i$, and $\max \left\{X_{j}\right\}$ and $\min \left\{\mathrm{X}_{j}\right\}$ indicate the minimum and maximum value of indicator $j$ among all years.

\subsection{Methods}

- The indexes for evaluation of Xinjiang High-speed Railway and the Tourism Economy.

We conducted a preliminary determination of the indexes of the Xinjiang High-speed Railway and the Tourism Economy system and developed a general system for coupling the relationship between these factors in accordance with previously conducted studies. The indexes were further selected through comparison of the correlation coefficients and significance levels, as well as qualitative analysis to place all the potential indexes in Xinjiang High-speed Railway and the Tourism Economy categories, and aim to gather an in-depth understanding of coupling relationship, moreover, to find out the interaction among those aspects. The final evaluation index system is shown in Table1 
number of years. The original data (2012-2017) describing the 7 indicators of Xinjiang province were processed using these steps on a time scale (TABLE I). The relevant values were subsequently calculated.

- The coupling coordination degree model (CCDM) The CCDM is given in formula (9).

$$
C=\left\{f(X) \cdot g(Y) /\left[\frac{f(X)+g(Y)}{2}\right]^{2}\right\}^{K},
$$

$D=\sqrt{C \cdot T}$ and $T=\alpha f(X)+\beta g(Y)$

Where $C$ represents the degree of coupling, $K$ is the regulation factor, $f(X)$ is the level of High-speed Railway System and $g(Y)$ is the Tourism Economy System quality. In cases in which the sum of $f(X)$ and $g(Y)$ are constant, C represents the degree of coupling between High-speed Railway and the Tourism Economy with the target of maximizing the product of $f(X)$ and $g(Y)$. Here, $f(X)$ and $g(Y)$ can be calculated by $S i$ described above. $D$ is the degree of coupling coordination and $T$ reflects the overall effect and level of the effect or level of High-speed Railway and the Tourism Economy. $\alpha$ and $\beta$ represent the contribution of Highspeed Railway and the Tourism Economy, respectively. In view of the fact that high-speed railway transportation is not the only driving force to promote the development of tourism economy, $\mathrm{a}=0.4$ and $\mathrm{b}=0.6$ are taken here; the value of $\mathrm{K}$ is $1 / 2$ in the following analysis of this paper.

\section{Results and discussion}

The entropy weight method determines the weight of each evaluation index of the high-speed railway transportation system and the tourism economic system, and the weight of each index is shown in Table2

Table3shows the Comprehensive Evaluation of the High-speed Railway System and the Tourism Economy System from 2013 to 2017. It can be seen from Table2that the Comprehensive Evaluation of the transportation system has been increasing year by year, especially after the opening of the Lanxin High Speed Railway in 2014. In 2015, the contribution value of the transportation system has nearly doubled.

After the opening of the Lanxin High Speed Railway in 2014, the coupling and coordination of the Xinjiang High Speed Railway transportation system and the tourism economic system have generally been increasing. Since 2014, the coupling coordination degree of Xinjiang's transportation system and tourism economic system has gradually shifted from a moderate imbalance to a slight imbalance and barely coordinated, and then reached the primary coordination in 2017 . It can be seen that the coupling and coordination relationship between the two is gradually strengthening and deepening. The relationship between the two is also closer, and the mutual promotion effect is more prominent. At the same time, the two are in a state of primary coordination on the whole, and there is room for development in the construction of the high-speed railway transportation system and the tourism economic system.

Therefore, the high-speed rail transportation system has an obvious positive effect on the tourism economy and promotes the development of the regional tourism economy, which is mainly reflected in the increase in the number of tourists, the increase in tourism income, the upgrading of the tourism industry structure and the interregional tourism cooperation. The high-speed rail has the characteristics of high safety, high speed, high comfort, convenient transfer, and short waiting time, which greatly reduces the time and space distance between regions, enhances travel comfort and expands short distances for tourists. The spatial scope of tourism has greatly stimulated tourism demand. The feature of shortening the time and distance of the high-speed rail, on the one hand, promotes the formation of a "1 hour traffic circle" and "1 day traffic circle" in the city, making it possible for interregional tourism cooperation. On the other hand, it also saves tourists' travel time and prolongs their visits. Over time, this change has promoted the transformation of the tourism industry from a single tourism industry to a comprehensive leisure tourism industry, which in turn promoted the development of in-depth tourism.

Table2. The weight of the High-speed Railway System and the Tourism Economy System

\begin{tabular}{|l|c|}
\hline \multicolumn{1}{|c|}{ index } & weight \\
\hline Passenger traffic (10000 persons) & 0.10306 \\
\hline Length of Railways in Operation (Km) & 0.09184 \\
\hline Passenger-Kilometers (100 million passenger-km) & 0.08317 \\
\hline Total Number of Overseas Vistor Arrivals (person) & 0.19778 \\
\hline Number of Domestic Visitors (10000 persons) & 0.20061 \\
\hline $\begin{array}{l}\text { Foreign Exchange Earnings from lnternational } \\
\text { Tourism (USD 10 000) }\end{array}$ & 0.18210 \\
\hline $\begin{array}{l}\text { Earnings from Domestic Tourism (100 million } \\
\text { yuan) }\end{array}$ & 0.14144 \\
\hline
\end{tabular}

Table3. Comprehensive Evaluation of the High-speed Railway System and the Tourism Economy System

\begin{tabular}{|c|c|c|c|c|c|}
\hline & $\mathbf{2 0 1 3}$ & $\mathbf{2 0 1 4}$ & $\mathbf{2 0 1 5}$ & $\mathbf{2 0 1 6}$ & $\mathbf{2 0 1 7}$ \\
\hline High-speed Railway & 0.03248 & 0.08610 & 0.15398 & 0.20845 & 0.27808 \\
\hline Tourism Economy & 0.06777 & 0.01314 & 0.17342 & 0.45406 & 0.72193 \\
\hline
\end{tabular}

Table4. C, T and D of the High-speed Railway System and the Tourism Economy System

\begin{tabular}{|c|c|l|c|c|c|}
\hline & $\mathbf{2 0 1 3}$ & $\mathbf{2 0 1 4}$ & $\mathbf{2 0 1 5}$ & $\mathbf{2 0 1 6}$ & $\mathbf{2 0 1 7}$ \\
\hline C & 0.209553 & 0.151 & 0.40389 & 0.534536 & 0.633642 \\
\hline T & 0.053655 & 0.042324 & 0.165648 & 0.355815 & 0.54439 \\
\hline D & 0.106036 & 0.079943 & 0.258658 & 0.436115 & 0.587323 \\
\hline
\end{tabular}

In addition, the development of tourism economy has also promoted the construction of high-speed rail to a certain extent. On the one hand, the tourism economy, as an important part of the regional economy, supports the construction of high-speed rail. On the other hand, as the spillover effect of the tourism economy on the regional economy becomes increasingly obvious, this will strengthen the attention of local governments and enterprises, and prompt them to accelerate the construction of public infrastructure. As an important part of the transportation system, high-speed rail will surely be 
more affected. At the same time, due to the improvement of people's living standards and the increase in leisure time, the demand for leisure and vacation tourism is gradually strong. The high-speed rail's high comfort, speed, and short transfers cater to the needs of tourists for fast and comfortable travel. The development of tourism economy will surely promote the construction of high-speed rail.

\section{Conclusions}

By studying the mechanism and development of Xinjiang High-speed Railway System and the Tourism Economy System, and establishing a coupling coordination model, it is concluded that Xinjiang high-speed railway and tourism economy are in a state of primary coordination. The mutual promotion between the Xinjiang High-speed Railway System and the Tourism Economy System should be strengthened. Accordingly, the following suggestions are made from the perspective of high-speed railway construction and tourism economic development.

\subsection{Improve the construction of high-speed railway network}

Local governments should pay attention to the importance of the high-speed railway transportation system in the development of the tourism economy, make full use of the geographical advantages of Xinjiang and do a good job in the planning of the development layout of Xinjiang's highspeed railway. Besides, they also should improve the network of Xinjiang's high-speed railway, and accelerate the construction of the "three districts and three states" main channel, improve travel convenience, attract tourists from economically developed areas, and promote the indepth development of Xinjiang's tourism economy.

\subsection{Speed up the upgrading and transformation of the tourism industry}

With the emergence of high-speed railway, the reduction of the space-time distance between regions has saved people travel time and extended travel time. This has caused people to put forward more demands for various aspects of tourism, and it has also led to the development of new types of tourism derivatives and it is particularly important to adjust the structure of the tourism industry. Therefore, it is necessary to fully integrate Xinjiang's historical features and environmental advantages, deeply explore the essence of Xinjiang's tourism culture, combine tourism, cultural landscape and leisure vacation, highlight the characteristics of Xinjiang's cultural customs and religious folk customs, and meet the needs of tourists at different levels.

\subsection{Create a "distribution center" for high-speed railway tourism}

Taking the high-speed railway area as the center, public buses such as buses, buses, and subways are added between various scenic spots and high-speed railway stations. In this way, a seamless connection between the high-speed railway and tourist attractions is realized. In addition, we can also design a batch of quality tourism routes and special tourism products.

\subsection{Speed up the integration of high-speed rail and tourism}

Transportation is not only the basic support and prerequisite for the development of tourism, the organic integration of the two is a new trend in the transformation and development of tourism. In many famous tourist attractions, the traffic infrastructure is far from meeting the requirements of passenger flow. This should rely on high-speed railways, intercity railways, civil aviation, high-grade highways, to build a "fast-forward" transportation network, improve the accessibility and convenience of tourist destinations, and enable tourists to quickly enter and exit the destinations. In addition, we must also pay attention to building roads in tourist attractions in accordance with local conditions, combining landscapes and tourism resources along the route to create a main road with multiple functions such as passage, leisure, experience, sports, fitness, culture, and education.

\section{References}

1. Bonnafous, The Regional Impact of the TGV, Transportation, 1987, 14(2), pp.127-137.

2. H. Okada, Features and Economic and Social Effects of the Shinkansen, Japan Railway and Transport Review, 1994, 3, pp.9-16.

3. Bruce Prideaux, The Role of the Transport System in Destination Development, Tourism Management, 2000, 21(1), pp.53-63.

4. D. Banister, Y. Berechman, Transport Investment and the Promotion of Economic Rowth, Journal of Transport Geography, 2001, 9(3), pp.209-218.

5. Paul Peeters, Major Environmental Impact of European Tourist Transport, Journal of Transport Geography, 2007, 15, pp.83-93

6. Sean Randolph, California High-Speed Railway Economic Benefits and Impacts in the San Francisco Bay Area, San Francisco: Bay Area Council Economic Institute, 2008, 10, pp.1-44.

7. Jose M. Urena, Philippe Menerault, Maddi Garmendia, The High-Speed Railway Challenge for Big Intermediate Cities: A National, Regional and Local Perspective, Cities, 2009, 26(5), pp.266-279.

8. Huang. Research on the Impact of High-speed Railway on Regional Tourism Development-Taking Wuhan-Guangzhou High-speed Railway as an Example[J]. East China Economic Management, 2011, 25(10): 47-49.

9. Wu, Shi. An Analysis of Tourism Economic Differences in the "High-speed Railway Era" Based on Geographic Concentration [J]. Statistics and Decision, 2014(24):145-147.

10. Yang, Deng. Comparative empirical study on the relationship between the tourism economy of my 
country's urban agglomeration and the high-speed railway transportation network pattern [J]. Statistics and Decision, 2019, 35(03): 133-136.

11. Chen, J., 2007. Rapid urbanization in China: a real challenge to soil protection and food security. Catena 69 (1), 1-15.

12. Chen, M.X., Lu, D.D., Zhang, H., 2009. Comprehensive evaluation and the driving factors of China's urbanization. Acta Geographica Sinica 64 (4), 387-398 (in Chinese with English abstract). 